\title{
Assessment of the efficacy and safety of intraperitoneal chemotherapy in patients with advanced gastric cancer in Chinese population: a meta-analysis
}

\author{
Jin $\mathrm{TANG}^{1}$, Jing YANG${ }^{2}$, Jinsong $\mathrm{HE}^{1}$, Jiebin $\mathrm{XIE}^{1}$, Pan WANG ${ }^{1}$, Shoujiang WEI ${ }^{1 \star ~(\mathbb{C})}$
}

\begin{abstract}
To investigate the safety and efficacy of intraoperative intraperitoneal chemotherapy in treating advanced gastric cancer. A randomized controlled trial (RCT) of gastric cancer surgery combined with intraoperative intraperitoneal chemotherapy for the efficacy and safety were screened by computer search PubMed, Medline, Springer, Elsevier Science Direct, Weipu, Wanfang and China National Knowledge Infrastructure (CNKI) with the last report up to October 2019. The control group underwent radical gastrectomy, and the experimental group underwent intraoperative intraperitoneal chemotherapy and radical gastrectomy. A total of 997 (Experimental group 453; Control group 544) participants were considered in this meta-analysis. Compared with the control group, the experimental group has higher 1-year survival rate [OR=2.40,95\% CI (1.34, 4.33), $\mathrm{P}=0.003$ ], 2-year survival rate $[\mathrm{OR}=3.45,95 \% \mathrm{CI}(2.08,5.75), \mathrm{P}<0.00001], 3$-year survival rate $[\mathrm{OR}=2.70,95 \% \mathrm{CI}(2.05,3.54), \mathrm{P}<0.00001]$ and 5 -year survival rate $[\mathrm{OR}=2.90,95 \% \mathrm{CI}(1.93,4.37), \mathrm{P}<0.00001]$. There is no significant difference in postoperative bleeding $(\mathrm{P}=0.95)$, postoperative infection $(\mathrm{P}=0.26)$, postoperative anastomotic leakage $(\mathrm{P}=0.41)$, and postoperative intestinal obstruction $(\mathrm{P}=0.11)$. Intraoperative intraperitoneal chemotherapy with advanced gastric cancer in the Chinese population can improve patients' survival rate after surgery and does not increase the incidence of postoperative complications, so it is clinically significant and safe.
\end{abstract}

Keywords: advanced gastric cancer; intraperitoneal chemotherapy; meta-analysis.

Practical Application: The efficiency and security of intraperitoneal chemotherapy in patients with advanced gastric cancer in Chinese population.

\section{Introduction}

According to the 2018 Global Cancer Report (Bray et al., 2018), there are 103,370 new cases and 782,685 deaths in 2018, ranking second and third in global morbidity and mortality, and the burden of disease is heavy. Gastric cancer is currently one of the highest mortality rates and serious cancers in all of the world (Xiao et al., 2018; Yu et al., 2019; Zare et al., 2019). The incidence of gastric cancer usually has no obvious symptoms and signs (Zhang et al., 2019). The detection rate of early gastric cancer is deficient, generally with no apparent symptoms. Most patients have developed advanced gastric cancer when they have symptoms (Wu et al., 2018; Xu et al., 2019). About 30\% of patients have signs of local spread at the time of diagnosis, and another 30\% have metastases at the time of diagnosis of gastric cancer. Radical resection is the primary means of treatment of gastric cancer. The peritoneum in the human body is one of the most common sites of recurrence of gastric cancer, and the prognosis after surgery is also very poor (Zhu et al., 2019).

With improved surgical instruments and surgical techniques, the 5-year survival rate of the standardized lymph node dissection is significantly improved. However, postoperative peritoneal implantation, liver metastasis, and recurrence of primary position are still the main factors affecting gastric cancer prognosis (Stewart et al., 2019). In recent years, establishing a multidisciplinary comprehensive treatment model based on surgery has extended the patient's survival (Li et al., 2019a; Choi et al., 2019; Uemura et al., 2018). However, patients' 5 -year survival rate did not significantly improve, about $14 \%$ to $43 \%$ of gastric cancer patients with peritoneal metastasis, and the peritoneum is a common site of recurrence metastasis (Zhu et al., 2019; Dahdaleh \& Turaga et al., 2018). Intraperitoneal chemotherapy is an effective treatment for advanced gastric cancer with peritoneal metastasis (Yarema et al., 2019; Beeharry et al., 2019; Peixoto et al., 2018). Peritoneal perfusion, warming effect, and the pernicious effect of chemotherapy drugs on tumor cells are used to achieve therapeutic purposes.

At present, peritoneal hyperthermic perfusion chemotherapy has been widely used in clinical practice and has achieved ideal clinical results. Peritoneal hyperthermic perfusion chemotherapy has excellent advantages in pharmacokinetics. It has an essential role in tumor cells' cytotoxic effect, sensitization to radiotherapy and chemotherapy, improvement of immune function, and inhibition of tumor metastasis (Zhu et al., 2019). Still, intraoperative intraperitoneal chemotherapy efficacy and safety in treating advanced gastric cancer in the Chinese population are unclear. This study systematically evaluated intraoperative intraperitoneal 
chemotherapy's effectiveness and safety in treating advanced gastric cancer in the Chinese population through meta-analysis.

\section{Material and methods}

\subsection{Search strategy}

Public databases were retrieved mainly including PubMed, Medline, Springer, Elsevier Science Direct, Weipu, Wanfang, and China National Knowledge Infrastructure (CNKI) with the last report up to October 2019. The keywords of "gastric", "stomach", "intraperitoneal", "chemotherapy", "carcinoma", "cancer", "tumors", "study" or "trial" were used for searching. Meanwhile, references from retrieved papers were checked for any additional studies. We only recruited data from the full-published Chinese or English paper, not any meeting or conference abstract.

\subsection{Included and excluded standards of studies}

Included standards of studies

Studies that met the following criteria were included: the design was a randomized controlled trial, regardless of English or Chinese language. The study subjects were aged $\geq 18$ years old. The study was a randomized and semi-randomized clinical controlled study with a follow-up of more than 2 years. The study object was advanced gastric cancer, which was confirmed by pathology before the operation. The observed indicators were the incidence of postoperative complications (postoperative bleeding, postoperative intestinal obstruction, anastomotic leakage, and postoperative infection) and a 1-5-year survival rate after surgery. The control group only underwent radical gastrectomy (including distal gastrectomy, total gastrectomy, total gastrectomy; laparoscopic or laparoscopic assistance; feasible D1 or D2 lymph node dissection). The experimental group underwent intraperitoneal chemotherapy and radical gastrectomy. The chemotherapy drug was dissolved in the diluent (no specific requirements for the chemotherapy drug and the dose) and heated to a particular temperature to soak the abdominal cavity. The postoperative treatment measures (such as postoperative chemotherapy) were the same in both groups. The objects were human beings, and participants' age was not limited; studies reported risk ratio as the outcome and sample size were not limited.

\subsection{Excluded criteria of studies}

Studies were excluded if one of the following existed: 1) Extensive abdominal metastasis or metastasis of other organs has been confirmed in early gastric cancer or during surgery. 2) The original literature study was not aimed at comparing the role of intraperitoneal chemotherapy in advanced gastric cancer. 3) The postoperative follow-up time was less than 2 years. 4) There was insufficient information for the extraction of data.

\subsection{Data extraction and quality evaluation}

According to the Cochrane Library Intervention System Evaluation Manual, two reviewers independently screened the literature based on the above inclusion criteria. By the pre-determined inclusion and exclusion criteria, two reviewers read the titles and abstracts of the literature, respectively and independently, excluded articles that failed to meet the criteria, and conducted full-text reading and data extraction on articles that meet the criteria. Discussion was adopted in the case of disagreements, and a third reviewer was introduced when necessary. Data extraction includes ${ }^{1}$ general data: title, authors, published date, etc.; ${ }^{2}$ basic features of the included literature: research object, interventions, number of cases, basic information of the patients; ${ }^{3}$ endpoints: postoperative complications (postoperative bleeding, postoperative infection, postoperative anastomotic leakage, and postoperative intestinal obstruction, etc.) and postoperative survival rate (1-year survival rate, 2-year survival rate, 3-year survival rate, and 5-year survival rate). After the data extraction of the literature is completed, cross-checking is performed to ensure the data's accuracy.

\subsection{Quality assessment}

Cochrane collaboration's tool for assessing the risk of bias for Systematic Reviews of Interventions 6.0 was used for evaluating randomized controlled trials.

\subsection{Meta-analysis methods}

Meta-analysis was performed using RevMan version 5.3 statistical software. Chi-square test was applied for heterogeneity analysis (I2 values $<25 \%$ are considered of low heterogeneity, between $25 \%$ to $50 \%$ moderate heterogeneity, and more than $50 \%$ are considered of high heterogeneity). If $\mathrm{P}>0.10, \mathrm{I}^{2}<50 \%$, the heterogeneity level was low, and fixed-effects model analysis was adopted (Mantel \& Haenszel, 1959), whereas $\mathrm{P} \leq 0.10, \mathrm{I}^{2} \geq 50 \%$ indicated a high level of heterogeneity, and a random-effects model was applied to assess sources of heterogeneity (DerSimonian \& Laird, 1986). The difference was statistically significant at $P<0.05$. The outcomes as risk ratios (ORs) of the postoperative complications effect (postoperative bleeding, postoperative infection, postoperative anastomotic leakage, and postoperative intestinal obstruction, etc.) and postoperative survival rate (1-year survival rate, 2-year survival rate, 3-year survival rate, and 5-year survival rate) association between experimental group and control group in patients of advanced gastric cancer were calculated. We evaluated publication bias of the postoperative complications effect and postoperative survival rate by using the funnel plot.

\section{Results}

\subsection{Characteristics of eligible studies}

There were 742 papers potentially relevant to the search terms (PubMed: 51; Medline: 30; Springer: 21; Elsevier Science Direct: 19; Weipu: 158; Wanfang: 246; CNKI: 217). There were 55 potentially relevant reports after removing duplicates or irrelevant studies. During screening the abstracts, 31 of these articles were excluded ( 15 were review articles; 16 not reported advanced gastric cancer). Then 24 studies were left for full publication review; of these, 13 were excluded (not reported Chinese population data). The study selection process is shown in Figure 1. 


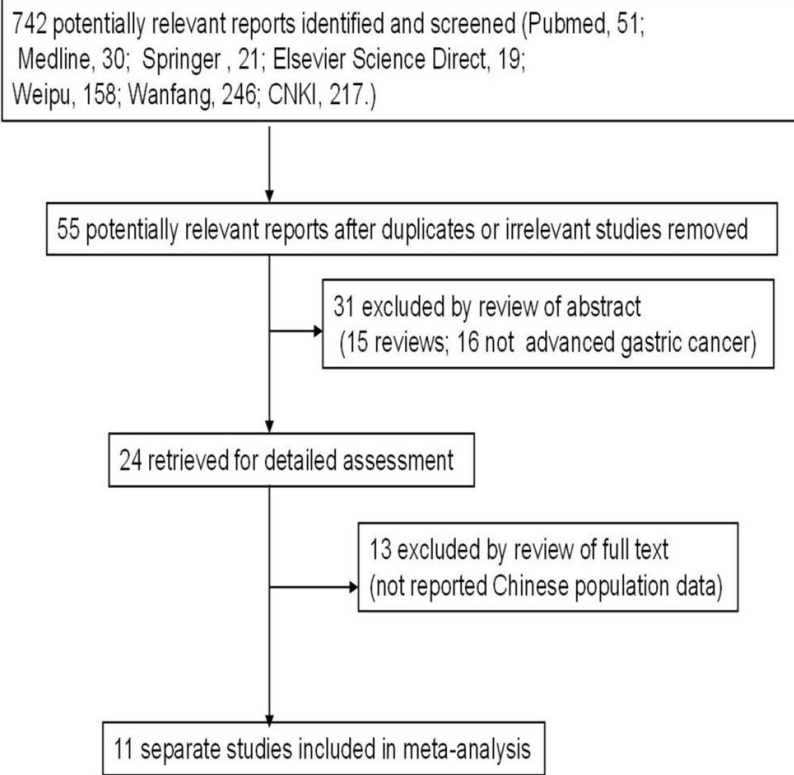

Figure 1. Flow diagram of included studies.

There were 11 studies (Chen et al., 2004, 2005; Wang et al., 2016; Jin, 2007; Shen et al., 2008; Liu, 2015; Guo \& Qin, 2016; He, 2017; Dai, 2017; Li et al., 2019b) in the meta-analysis, and the characteristics of the included studies were presented in Table 1. The included studies were published between 2004 and 2019. A total of 997 (Experimental group 453; Control group 544) were conducted in this meta-analysis. The studies' sample sizes were between 39 and 156. Studies had been carried out in China. The risk of bias summary is shown in Figure 2, and the risk of bias graph is shown in Figure 3.

\subsection{Meta-analysis of the postoperative complications association between experimental group and control group}

Crude ORs with 95\% CIs were used to assess the postoperative complications association between the experimental and control groups in patients of advanced gastric cancer. As shown in Figure 4, no significant heterogeneities $\left(P\right.$-value by $\chi^{2}$-based $Q$ testing $>0.1$ and $I^{2}=0 \%$ ) were observed, so we used the fixed effect model to determine the postoperative complications association between the experimental group and control group. There is no significant difference in postoperative bleeding $(\mathrm{OR}=0.94$, $95 \% \mathrm{CI}(0.13,6.69), \mathrm{P}=0.95)$, postoperative infection $(\mathrm{OR}=0.59$, $95 \% \mathrm{CI}(0.23,1.48), \mathrm{P}=0.26)$, postoperative anastomotic leakage $(\mathrm{OR}=0.66,95 \% \mathrm{CI}(0.24,1.78), \mathrm{P}=0.41)$ and postoperative intestinal obstruction $(\mathrm{OR}=0.55,95 \% \mathrm{CI}(0.27,1.14), \mathrm{P}=0.11)$.

\subsection{Meta-analysis of the postoperative survival rate association between experimental group and control group}

Crude ORs with 95\% CIs were used to assess the postoperative survival rate association between the experimental and control groups in advanced gastric cancer patients. As shown in Figure 5, no significant heterogeneities $\left(P\right.$-value by $\chi^{2}$-based $Q$ testing $>0.1$ and $I^{2}=0 \%$ ) were observed, so we used the fixed effect model to

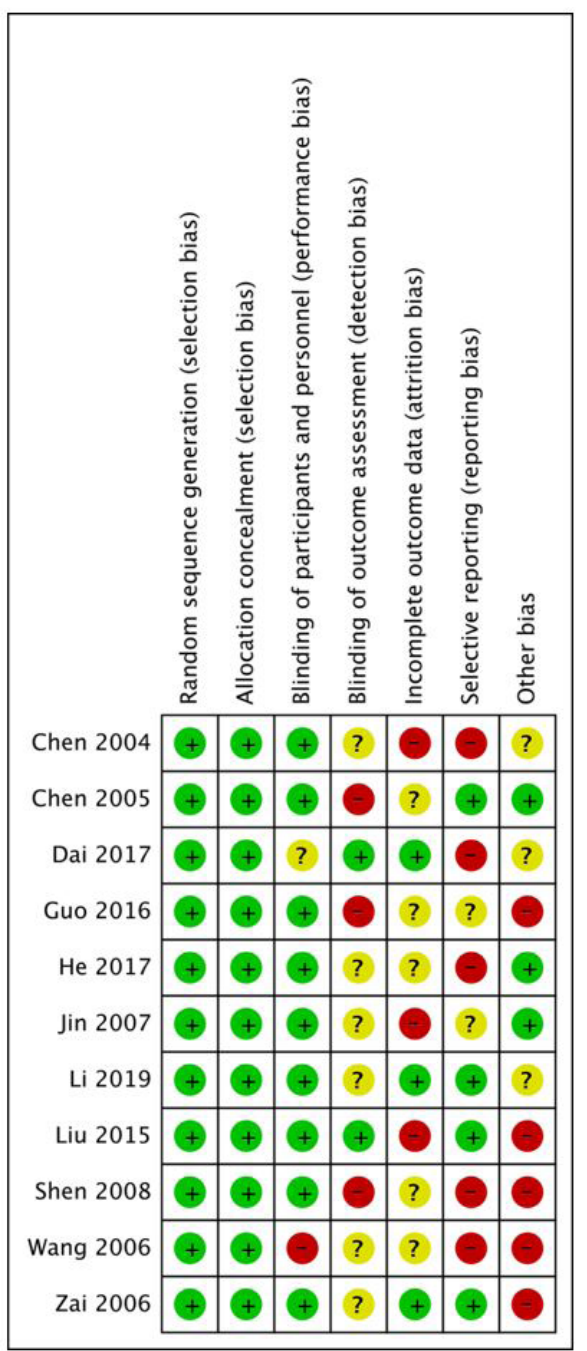

Figure 2. Risk of bias summary.

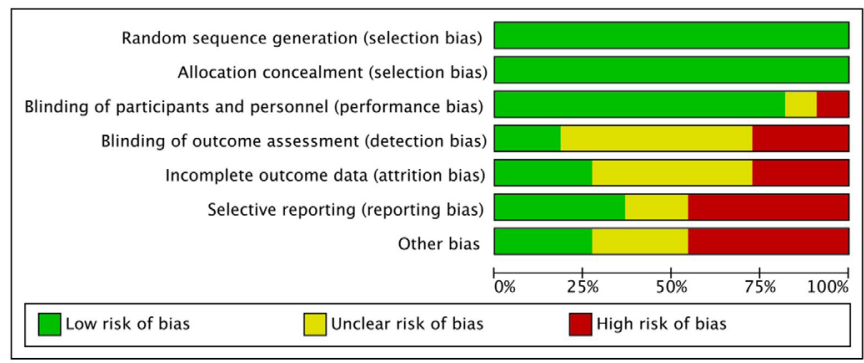

Figure 3. Risk of bias graph.

determine the postoperative survival rate association between the experimental group and control group. Our results showed that compared with the control group, the experimental group has higher 1 -year survival rate $[\mathrm{OR}=2.40,95 \% \mathrm{CI}(1.34,4.33)$, $\mathrm{P}=0.003]$, 2-year survival rate $[\mathrm{OR}=3.45$, 95\%CI $(2.08,5.75)$, $\mathrm{P}<0.00001]$, 3-year survival rate $[\mathrm{OR}=2.70,95 \% \mathrm{CI}(2.05,3.54)$, $\mathrm{P}<0.00001]$ and 5 -year survival rate $[\mathrm{OR}=2.90,95 \% \mathrm{CI}(1.93$, 4.37), $\mathrm{P}<0.00001]$. 
Table 1. General demographic characteristics of the subjects.

\begin{tabular}{|c|c|c|c|c|c|c|c|c|}
\hline \multirow[b]{2}{*}{ Study } & \multirow[b]{2}{*}{$\begin{array}{c}\text { Intraperitoneal } \\
\text { chemotherapy regimen }\end{array}$} & \multirow[b]{2}{*}{$\begin{array}{l}\text { Postoperative } \\
\text { chemotherapy }\end{array}$} & \multicolumn{3}{|c|}{ Experimental group } & \multicolumn{3}{|c|}{ Control group } \\
\hline & & & $\begin{array}{c}\text { Sample } \\
\text { size }\end{array}$ & $\begin{array}{c}\text { Age, years } \\
\text { (mean } \pm \text { SD or } \\
\text { min-max) }\end{array}$ & Male (n) & $\begin{array}{l}\text { Sample } \\
\text { size }\end{array}$ & $\begin{array}{c}\text { Age, years } \\
\text { (mean } \pm \text { SD or } \\
\text { min-max) }\end{array}$ & Male (n) \\
\hline Chen et al. (2005) & 5 -FU $0.5 \mathrm{~g} / \mathrm{L}, \mathrm{MMC} 8 \mathrm{mg} / \mathrm{L}$ & FAM & 30 & $23-75$ & 25 & 30 & $25-72$ & 23 \\
\hline Wang et al. (2006) & DDP $80-100 \mathrm{mg}$ & FM & 37 & $21-72$ & 18 & 31 & $26-75$ & 17 \\
\hline Zai et al. (2006) & DDP $80-100 \mathrm{mg}$ & NA & 49 & $42-71$ & 38 & 47 & $40-69$ & 38 \\
\hline Shen et al. (2008) & DDP $120-150 \mathrm{mg}$ & FOLFOX4 & 50 & $21-70$ & 22 & 100 & $18-72$ & 60 \\
\hline Liu (2015) & OXA $350 \mathrm{mg}$ & NA & 19 & 51.9 & 12 & 20 & 52.8 & 14 \\
\hline Guo \& Qin (2016) & DDP 100 mg, MMC 30 mg & NA & 50 & $53.7 \pm 8.8$ & 32 & 50 & $53.3 \pm 8.5$ & 30 \\
\hline $\mathrm{He}(2017)$ & 5-FU $1500 \mathrm{mg}$ & mFOLFOX6 & 47 & $58.9 \pm 7.6$ & 25 & 49 & $59.6 \pm 8.2$ & 28 \\
\hline Dai (2017) & $\mathrm{NaCl} 3000-5000 \mathrm{~mL}$ & mFOLFOX6 & 20 & $56.0 \pm 6.1$ & 12 & 20 & $57.5 \pm 6.5$ & 11 \\
\hline
\end{tabular}

NA= not available. DDP: cisplatin; OXA: Oxaliplatin; 5-FU: 5-Fluorouracil; MMC: mitomycin C; FAM: 5-Fluorouracil, doxorubicin, and mitomycin; ELF: Etoposide, l-leucovorin and fluorouracil; FOLFOX4: 5-fluomumcil/leucovorin combined and oxaliplatin; mFOLFOX6: modified 5-fluorouracil, folinic acid, and oxaliplatin.

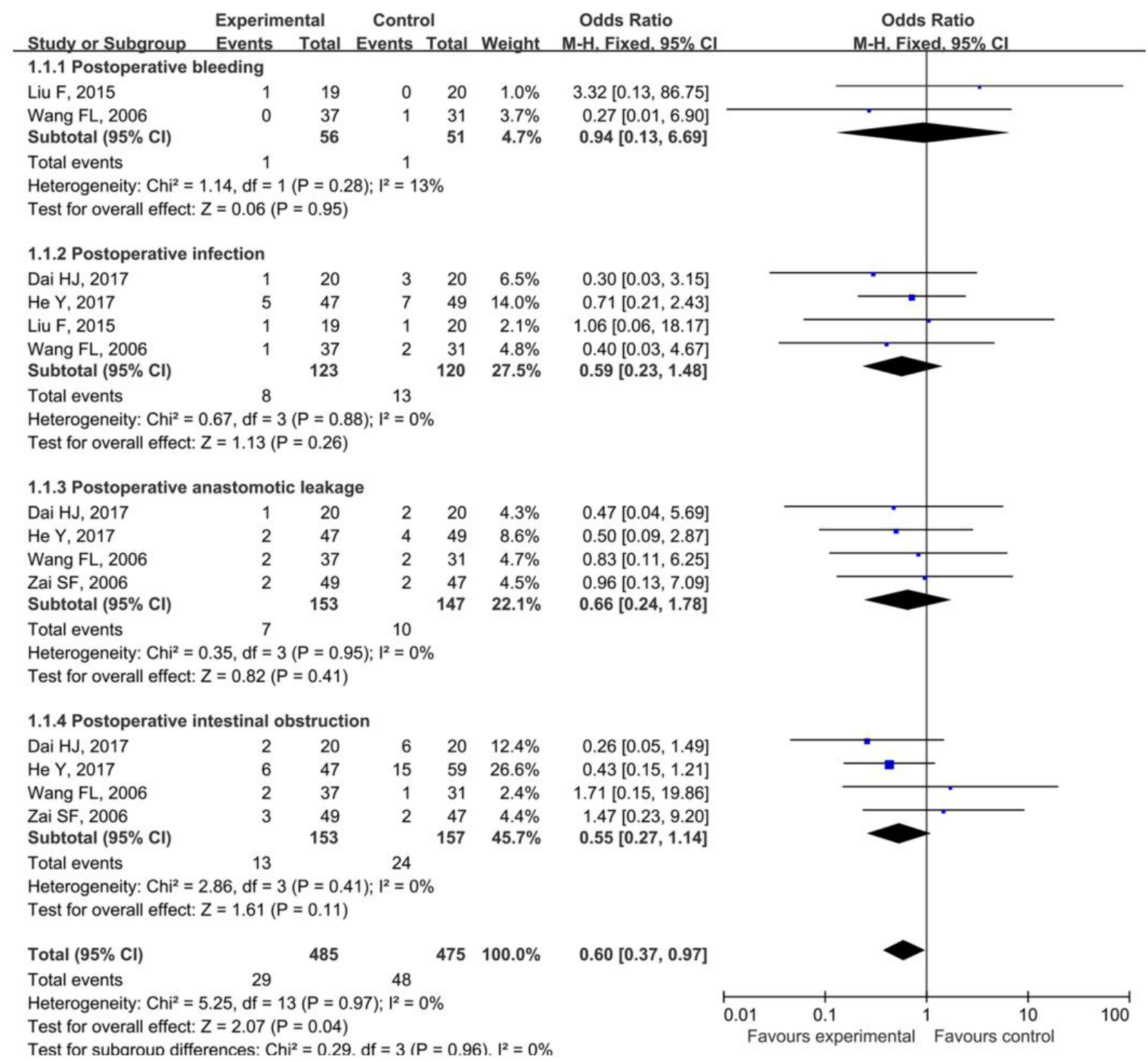

Figure 4. Forest plot of the postoperative complications association between experimental group and control group. 


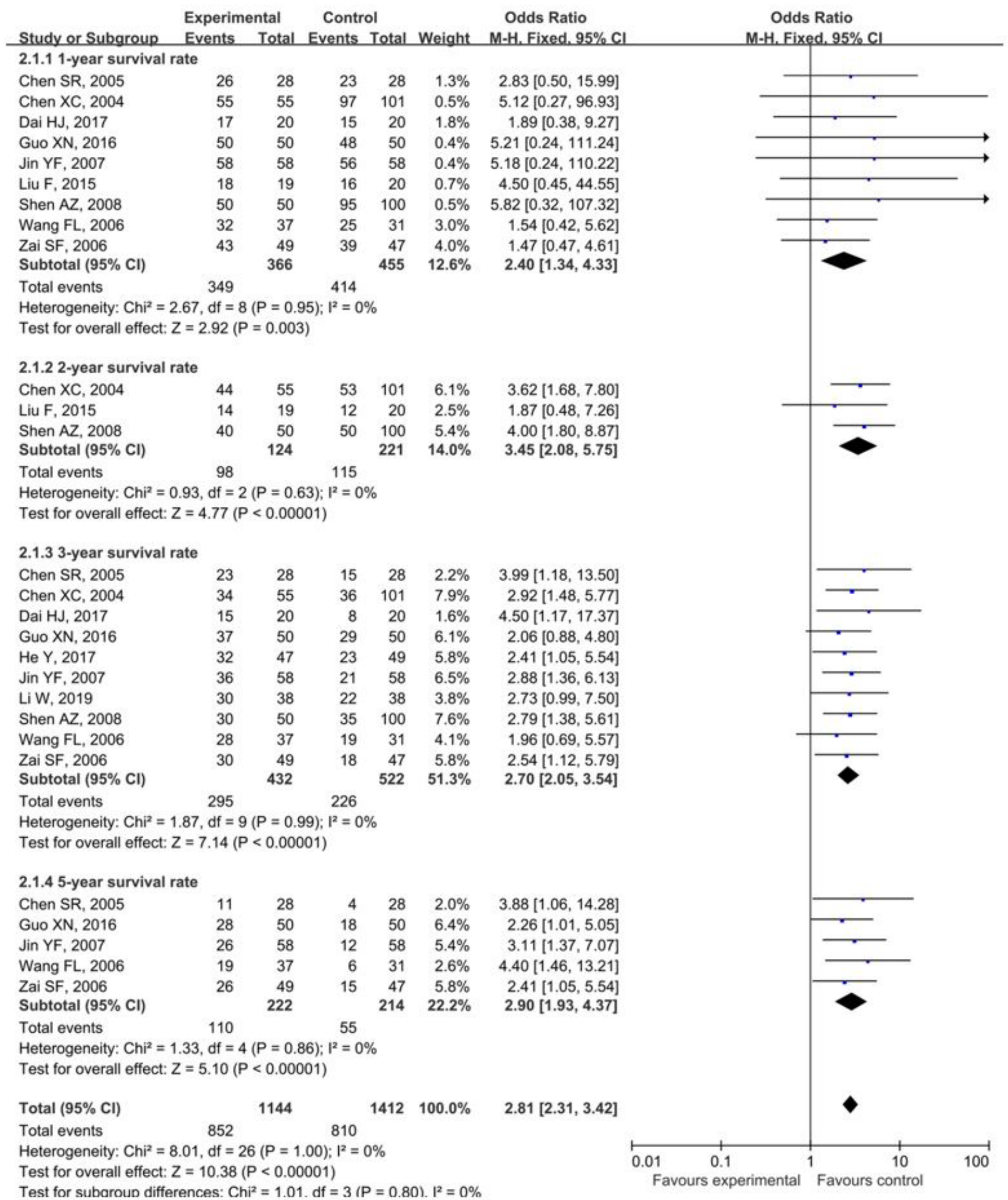

Figure 5. Forest plot of the postoperative survival rate association between experimental group and control group.

\subsection{Publication bias}

The funnel plot was performed to assess the publication bias of the included studies. No obvious publication bias was found under all models comparison for postoperative complications and postoperative survival rates. The results were shown in Figure 6 and 7.

\section{Discussion}

Gastric cancer is a common malignant tumor in the clinic (Khorfan et al., 2020; Fanotto et al., 2019). The main metastasis route of gastric cancer is peritoneal dissemination. Complications after gastric cancer surgery are common factors leading to death. Due to the plasma-peritoneal barrier's presence, the clinical 


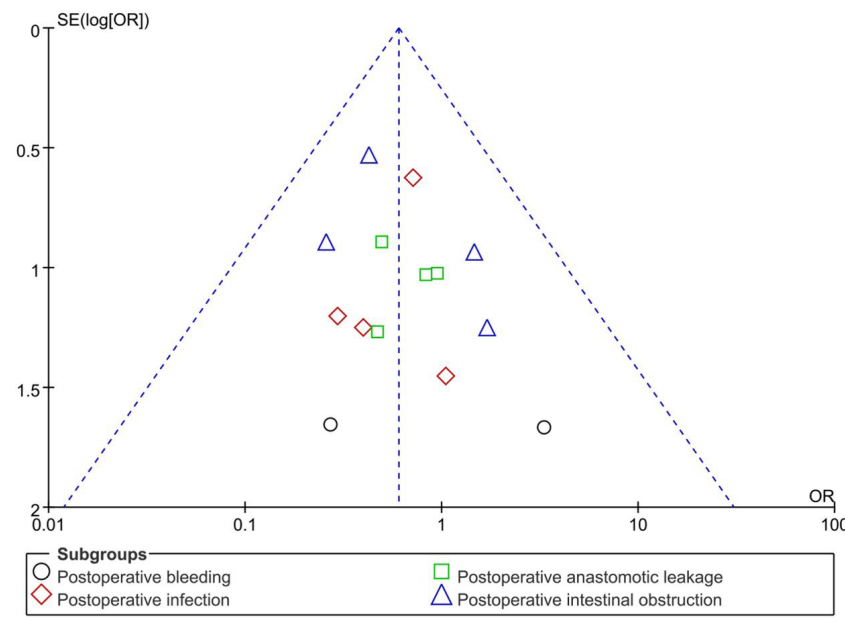

Figure 6. Funnel plot of the postoperative complications association between experimental group and control group.

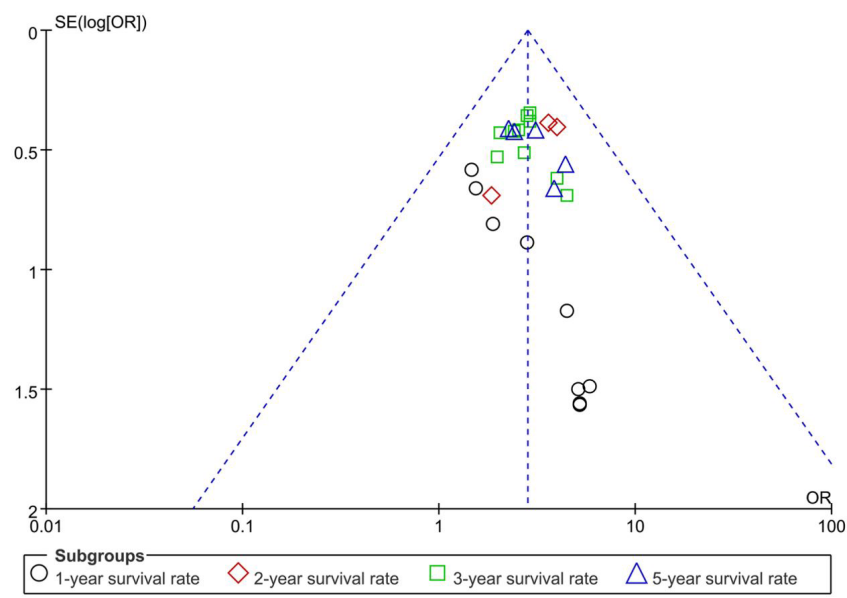

Figure 7. Funnel plot of the postoperative survival rate association between experimental group and control group.

efficacy of intravenous systemic chemotherapy and regional chemotherapy is not very good. The intraperitoneal hyperthermic perfusion chemotherapy developed based on intraperitoneal chemotherapy mainly combines hyperthermia and chemotherapy to provide a new way to treat gastric cancer patients.

The intraperitoneal chemotherapy mainly achieves the therapeutic effect through the high-temperature environment of the abdominal cavity, the liquid's flushing action, and the toxic effect of the chemotherapy drug (Leiting \& Grotz, 2019; Kim et al., 2018; Coccolini et al., 2018). The peritoneal thickness is about $90 \mu \mathrm{m}$, mainly composed of mesothelial cells and a layer of membranous tissue formed by the support of connective tissue. Tumor cells that break through the serosa layer can stay in the peritoneum. Studies have shown that tumor cells can only survive for $1 \mathrm{~h}$ at $43^{\circ} \mathrm{C}$, while normal cells can survive for $1 \mathrm{~h}$ at $47^{\circ} \mathrm{C}$ high temperatures and accelerate tumor cell death (Garofalo et al., 2006). After the intraperitoneal chemotherapy drugs and liquids are placed, the high temperature can increase the cell membrane and tumor cells' vascular permeability, which is beneficial to the absorption and penetration of chemotherapy drugs. The cancer nodules in the peritoneal cavity are long-term in high-concentration and high-temperature chemotherapy drugs (Ushimaru et al., 2019). The cytotoxic effect of chemotherapy drugs is strengthened. The mobile chemotherapy solution is excreted to achieve therapeutic purposes. This study showed no statistically significant difference in postoperative complications (postoperative bleeding, postoperative infection, postoperative anastomotic leakage, and postoperative intestinal obstruction) between the experimental group and the control group, and the safety was feasible.

Continuous circulation of intraperitoneal hyperthermic perfusion chemotherapy combines hyperthermia and chemotherapy based on traditional chemotherapy, and enhances chemotherapy drugs' efficacy using hyperthermia. Its most significant feature is that it can directly contact the chemotherapeutic drugs and tumor cells, increase the local drug concentration of the lesions, and prolong the drugs' action time. Thereby improving the therapeutic effect and reducing the rate of postoperative tumor metastasis or recurrence. Intraperitoneal hyperthermic perfusion chemotherapy itself has a pernicious impact on tumor cells, mainly in the destruction of tumor cells' membranous structure, inhibition of angiogenesis, improvement of immune function, and induction of apoptosis (Zhu et al., 2019). Intraperitoneal hyperthermic perfusion chemotherapy for advanced gastric cancer is mainly used for cytological examination of peritoneal washing fluid. Free cancer cells are positive, or the naked eye sees tumor invading the serosa without other visible lesions visible to the naked eye. Patients with radical resection can be performed (Mitrousias et al., 2019; Imagami et al., 2019). Seshadri $\mathrm{R}$ believes that the basic principle of intraoperative peritoneal hyperthermic chemotherapy for the prevention and treatment of advanced gastric cancer is to dilute gastric cancer cells by diluting free gastric cancer cells and chemotherapy drugs in the peritoneal cavity (Seshadri \& Glehen, 2016). The principle of treatment of intraperitoneal chemotherapy in advanced gastric cancer remains to be further studied. In this study, the results demonstrated that intraoperative intraperitoneal chemotherapy combined with radical gastrectomy could improve the postoperative survival rate (1-year, 2-year, 3-year, and 5-year survival rate) to treat advanced gastric cancer. At the same time, intraoperative intraperitoneal chemotherapy is simple, feasible, and can be promoted in clinical practice. Besides, in-depth studies of specific drugs and specific doses of intraperitoneal chemotherapy, chemotherapeutic drug sensitivity, and penetration depth should be explored to provide more evidence for patients' prolonged survival with intraperitoneal chemotherapy.

Limitations of the present study: (1) By definition and study design, chemotherapy regimen with the same efficacy but different regimens also have other effects on advanced gastric cancer. Therefore, the quantitative meta-analysis of different kinds of chemotherapy regimens will have certain defects. (2) There are few high-quality randomized controlled studies, including the small number of subjects, the lack of description of random methods, allocation concealment, and follow-up implementation. (3) This study did not strictly limit the age, course of the disease, which will also cause a risk of bias in evaluating efficacy. Therefore, the results and conclusion should be used with caution. 


\section{Conclusion}

Intraoperative intraperitoneal chemotherapy with advanced gastric cancer in the Chinese population can improve patients' survival rate after surgery and does not increase the incidence of postoperative complications, so it is clinically significant and safe. However, more multicenter RCTs with a large sample number and high quality should verify the conclusion mentioned above.

\section{Conflict of interest}

The authors declare that they have no competing interest.

\section{References}

Beeharry, M. K., Zhu, Z. L., Liu, W. T., Yao, X. X., Yan, M., \& Zhu, Z. G. (2019). Prophylactic HIPEC with radical D2 gastrectomy improves survival and peritoneal recurrence rates for locally advanced gastric cancer: personal experience from a randomized case control study. BMC Cancer, 19(1), 932. http://dx.doi.org/10.1186/s12885-0196125-z. PMid:31533660.

Bray, F., Ferlay, J., Soerjomataram, I., Siegel, R. L., Torre, L. A., \& Jemal, A. (2018). Global cancer statistics 2018: GLOBOCAN estimates of incidence and mortality worldwide for 36 cancers in 185 countries. CA: A Cancer Journal for Clinicians, 68(6), 394-424. http://dx.doi. org/10.3322/caac.21492. PMid:30207593.

Chen, S. R., Zhao, F., Zuo, Z., \& Jiansheng, L. V. (2005). Effect of peritoneal heat perfusion chemotherapy on prognosis in radical gastrectomy. Journal of Youjiang Medical University for Nationalities, 27(3), 357.

Chen, X., Luo, J., Liu, H., Chen, Y., Hu, Y., Li, T., Lin, T., Zhu, Y., Zhao, M., Chen, H., Li, G., \& Yu, J. (2004). Clinical study of intraoperative intraperitoneal hyperthermic chemotherapy for gastric cancer. Chinese Journal of Gastrointestinal Surgery, 21(5), 593-599. PMid:29774943.

Choi, Y. I., Chung, J. W., Kim, K. O., Kwon, K. A., Kim, Y. J., Park, D. K., Ahn, S. M., Park, S. H., Sym, S. J., Shin, D. B., Kim, Y. S., Sung, K. H., Baek, J. H., \& Lee, U. (2019). Concordance rate between clinicians and Watson for Oncology among patients with advanced gastric cancer: early, real-world experience in Korea. Canadian Journal of Gastroenterology \& Hepatology, 2019, 8072928. http://dx.doi. org/10.1155/2019/8072928. PMid:30854352.

Coccolini, F., Fugazzola, P., Ansaloni, L., Sartelli, M., Cicuttin, E., Leandro, G., De' Angelis, G. L., Gaiani, F., Di Mario, F., Tomasoni, M., \& Catena, F. (2018). Advanced gastric cancer: the value of systemic and intraperitoneal chemotherapy. Acta bio-medica Atenei Parmensis, 89(8-S), 104-109. http://dx.doi.org/10.23750/ abm.v89i8-S.7904. PMid:30561427.

Dahdaleh, F. S., \& Turaga, K. K. (2018). Evolving treatment strategies and outcomes in advanced gastric cancer with peritoneal metastasis. Surgical Oncology Clinics of North America, 27(3), 519-537. http:// dx.doi.org/10.1016/j.soc.2018.02.006. PMid:29935687.

Dai HJ. (2017). Clinical efficacy of intraperitoneal hyperthermic perfusion chemotherapy in locally advanced gastric cancer operation. Chinese Community Doctors, 33(25), 38-39.

DerSimonian, R., \& Laird, N. (1986). Meta-analysis in clinical trials. Controlled Clinical Trials, 7(3), 177-188. http://dx.doi.org/10.1016/01972456(86)90046-2. PMid:3802833.

Fanotto, V., Fornaro, L., Bordonaro, R., Rosati, G., Rimassa, L., Di Donato, S., Santini, D., Tomasello, G., Leone, F., Silvestris, N., Stragliotto, S., Scartozzi, M., Giampieri, R., Nichetti, F., Antonuzzo, L., Cinieri, S., Avallone, A., Pellegrino, A., Melisi, D., Vasile, E., Gerratana, L., \& Aprile, G. (2019). Second-line treatment efficacy and toxicity in older vs. non-older patients with advanced gastric cancer: a multicentre real-world study. Journal of Geriatric Oncology, 10(4), 591-597. http:// dx.doi.org/10.1016/j.jgo.2018.11.009. PMid:30551958.

Garofalo, A., Valle, M., Garcia, J., \& Sugarbaker, P. H. (2006). Laparoscopic intraperitoneal hyperthermic chemotherapy for palliation of debilitating malignant ascites. European Journal of Surgical Oncology, $32(6), 682-685$.

Guo, X. N., \& Qin, Y. (2016). Effect of intraperitoneal warm-heat perfusion chemotherapy in radical gastrectomy on postoperative recurrence and metastasis. Qingdao Medical Journal, 48(1), 57-58.

He, Y. (2017). Clinical Trial of Intra-operative Precisa Hyperthermic Intraperitoneal Chemotherapy for Advanced Gastric Cancer. Xinxiang: Xinxiang Medical University.

Imagami, T., Takayama, S., Hattori, T., Matsui, R., Sakamoto, M., Kani, H., Kurokawa, S., \& Fujiwara, T. (2019). A case of synchronous advanced gastric cancer and locally advanced prostate cancer with combined laparoscopic and robotic surgery: a case report. International Journal of Surgery Case Reports, 56, 82-85. http:// dx.doi.org/10.1016/j.ijscr.2019.02.032. PMid:30852372.

Jin, Y. F. (2007). Effect of perotoneal heat perfusion chemotherapy on prognosis in radical gastrectomy. Zhejiang Clinical Medical Journal, 9(3), 357-358.

Khorfan, R., Schlick, C. J. R., Yang, A. D., Odell, D. D., Bentrem, D. J., \& Merkow, R. P. (2020). Utilization of minimally invasive surgery and its association with chemotherapy for locally advanced gastric cancer. Journal of Gastrointestinal Surgery, 24(2), 243-252. http:// dx.doi.org/10.1007/s11605-019-04410-x. PMid:31749097.

Kim, D. W., Park, D. G., Song, S., \& Jee, Y. S. (2018). Cytoreductive surgery and hyperthermic intraperitoneal chemotherapy as treatment options for peritoneal metastasis of advanced gastric cancer. Journal of Gastric Cancer, 18(3), 296-304. http://dx.doi.org/10.5230/jgc.2018.18. e32. PMid:30276006.

Leiting, J. L., \& Grotz, T. E. (2019). Advancements and challenges in treating advanced gastric cancer in the West. World Journal of Gastrointestinal Oncology, 11(9), 652-664. http://dx.doi.org/10.4251/ wjgo.v11.i9.652. PMid:31558971.

Li, Q., Xu, X., Su, D., Zhou, T., Wang, G., \& Li, Z. (2019a). Long-term survival of an elderly patient with advanced gastric cancer after combination therapy: a case report and literature review. BMC Cancer, 19(1), 459. http://dx.doi.org/10.1186/s12885-019-5683-4. PMid:31096933.

Li, W., Xiong, X., Liu, G. C., \& Chen, Z. S. (2019b). Analysis on the clinical effect and prognosis of continuous circulating intraperitoneal hyperthermic perfusion chemotherapy in radical gastrectomy. Clinical Medical \& Engineering, 26(6), 741-742.

Liu, F. (2015). Analysis of the clinical effect of peritoneal heat perfusion chemotherapy in advanced gastric cancer surgery. China Practical Medicine, 10(4), 147-148.

Mantel, N., \& Haenszel, W. (1959). Statistical aspects of the analysis of data from retrospective studies of disease. Journal of the National Cancer Institute, 22(4), 719-748. PMid:13655060.

Mitrousias, A. S., Makris, M. C., Zani, J. R., Kornaropoulos, M., Tsilimigras, D. I., Chrysikos, D., Michalopoulos, N. V., Spartalis, E., Moris, D., \& Felekouras, E. (2019). Laparoscopic versus open gastrectomy with $\mathrm{D} 2$ lymph node dissection for advanced gastric cancer: a systematic review. Journal of BUON, 24(3), 872-882.

Peixoto, R. D., de Sousa, T. T., Silva, P. A. I. A., de Meirelles, L. R., \& Teixeira, C. H. A. (2018). Complete response for more than 4 years following neoadjuvant FOLFOX and cytoreductive surgery with hyperthermic intraperitoneal chemotherapy for a patient with advanced 
gastric cancer with extensive peritoneal carcinomatosis. Case Reports in Oncology, 11(2), 305-310. http://dx.doi.org/10.1159/000488978. PMid:29928208.

Seshadri, R. A., \& Glehen, O. (2016). The role of hyperthermic intraperitoneal chemotherapy in gastric cancer. Indian Journal of Surgical Oncology, 7(2), 198-207. http://dx.doi.org/10.1007/s13193016-0502-8. PMid:27065710.

Shen, A. Z., Xing, G. C., Zhang, H. M., \& Zhao, X. S. (2008). Clinical study of intraoperative intraperitoneal hyperthermic chemotherapy for gastric cancer. Journal of Modern Oncology, 16(3), 411-412.

Stewart, C., Chao, J., Chen, Y. J., Lin, J., Sullivan, M. J., Melstrom, L., Hyung, W. J., Fong, Y., Paz, I. B., \& Woo, Y. (2019). Multimodality management of locally advanced gastric cancer-the timing and extent of surgery. Translational Gastroenterology and Hepatology, 4, 42. http://dx.doi.org/10.21037/tgh.2019.05.02. PMid:31231709.

Uemura, S., Iwashita, T., Iwata, K., Mukai, T., Osada, S., Sekino, T., Adachi, T., Kawai, M., Yasuda, I., \& Shimizu, M. (2018). Endoscopic duodenal stent versus surgical gastrojejunostomy for gastric outlet obstruction in patients with advanced pancreatic cancer. Pancreatology, 18(5), 601-607. https://doi.org/10.1016/j.pan.2018.04.015.

Ushimaru, Y., Fujiwara, Y., Shishido, Y., Omori, T., Yanagimoto, Y., Sugimura, K., Moon, J. H., Miyata, H., \& Yano, M. (2019). Condition mimicking peritoneal metastasis associated with preoperative staging laparoscopy in advanced gastric cancer. Asian Journal of Endoscopic Surgery, 12(4), 457-460. http://dx.doi.org/10.1111/ ases.12678. PMid:30590871.

Wang, F. L., Hou, A. J., \& Peng, Z. (2016). Clinical study on peritoneal hypotonic heat perfusion in radical gastrectomy. Clinical Journal of Medical Officer, 34(1), 17-19.

Wu, D. M., Wang, S., Wen, X., Han, X. R., Wang, Y. J., Shen, M., Fan, S. H., Zhang, Z. F., Zhuang, J., Shan, Q., Li, M. Q., Hu, B., Sun, C. H., Lu, J., \& Zheng, Y. L. (2018). Survival benefit of three different therapies in postoperative patients with advanced gastric cancer: a network meta-analysis. Frontiers in Pharmacology, 9, 929. http:// dx.doi.org/10.3389/fphar.2018.00929. PMid:30210338.

Xiao, S. M., Xu, R., Tang, X. L., Ding, Z., Li, J. M., \& Zhou, X. (2018). Conversion therapy for advanced gastric cancer with trastuzumab combined with chemotherapy: A case report. Oncology Letters, 16(2), 2085-2090. http://dx.doi.org/10.3892/ol.2018.8942. PMid:30008904.
Xu, Y., Hua, J., Li, J., Shi, L., Xue, H., Shuang, J., \& Du, J. (2019). Longterm outcomes of laparoscopic versus open gastrectomy for advanced gastric cancer: a large cohort study. American Journal of Surgery, 217(4), 750-756. http://dx.doi.org/10.1016/j.amjsurg.2018.07.012. PMid:30055806.

Yarema, R., Mielko, J., Fetsych, T., Ohorchak, M., Skorzewska, M., Rawicz-Pruszyński, K., Mashukov, A., Maksimovsky, V., Jastrzębski, T., Polkowski, W., Gyrya, P., Kovalchuk, Y., Safiyan, V., Karelin, I., Kopetskiy, V., Kolesnik, O., Kondratskiy, Y., \& Paskonis, M. (2019). Hyperthermic intraperitoneal chemotherapy (HIPEC) in combined treatment of locally advanced and intraperitonealy disseminated gastric cancer: a retrospective cooperative central-eastern European study. Cancer Medicine, 8(6), 2877-2885. http://dx.doi.org/10.1002/ cam4.2204. PMid:31033239.

Yu, J., Huang, C., Sun, Y., Su, X., Cao, H., Hu, J., Wang, K., Suo, J., Tao, K., He, X., Wei, H., Ying, M., Hu, W., Du, X., Hu, Y., Liu, H., Zheng, C., Li, P., Xie, J., Liu, F., Li, Z., Zhao, G., Yang, K., Liu, C., Li, H., Chen, P., Ji, J., \& Li, G. (2019). Effect of laparoscopic vs open distal gastrectomy on 3-year disease-free survival in patients with locally advanced gastric cancer: the CLASS-01 randomized clinical trial. Journal of the American Medical Association, 321(20), 1983-1992. http://dx.doi.org/10.1001/jama.2019.5359. PMid:31135850.

Zai, S.F., Wang, J., Guo, M., \& Xie, Z.B. (2006). A clinical study of Intraoperative Intraperitoneal Hyperthermic Chemotherapy for gastric cancer. Journal of Basic and Clinical, 19(2), 122-123.

Zare, A., Alipoor, B., Omrani, M. D., Zali, M. R., Malekpour Alamdari, N., \& Ghaedi, H. (2019). Decreased mir-155-5p, mir-15a, and mir186 expression in gastric cancer is associated with advanced tumor grade and metastasis. Iranian Biomedical Journal, 23(5), 338-343. http://dx.doi.org/10.29252/ibj.23.5.5. PMid:31103022.

Zhang, H. W., Yang, J. J., Zheng, J. Y., Sun, L., Yang, X. W., \& Li, G. C. (2019). Postoperative intraperitoneal hyperthermic perfusion improve survival for advanced gastric cancer. Medicine, 98(30), e16598. http://dx.doi.org/10.1097/MD.0000000000016598. PMid:31348304.

Zhu, L., Xu, Y., Shan, Y., Zheng, R., Wu, Z., \& Ma, S. (2019). Intraperitoneal perfusion chemotherapy and whole abdominal hyperthermia using external radiofrequency following radical D2 resection for treatment of advanced gastric cancer. International Journal of Hyperthermia, 36(1), 402-407. http://dx.doi.org/10.1080/02656736.2019.157937 2. PMid:30829551. 